поняття «сучасний». Використовується актуальний досвід музикознавчого дискурсу, виявляються естетичні тенденції еволюції пізнього стилю Р. Штрауса. Ставиться питання про значення комічної естетичної тенденції у розвитку сучасного музичного театру.

Ключові слова: оперна поетика, стиль, темпоральна антиномічність, пізньостильове композиторське мислення.

Zhang Kai. Temporality as a condition of stylistic characteristics of the Richard Strauss' later operas: the experience of musicological discourse. The article presents an updated approach to the study of late operatic works by Richard Strauss, based on the involvement of the temporal characteristics. The terminological position of concept of «contemporary» is determined. The actual experience of musicological discourse is used, the aesthetic trends in the evolution of the Richard Strauss's late style are defined. The question of the significance of the comic aesthetic trends in contemporary musical theater is raised.

Keywords: opera poetics, style, temporal antinomy, later-style composer thinking.

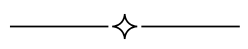

УДК $78.03 / 782.1$

\title{
Чжси Инь \\ РИТОРИЧЕСКИЕ ИСТОКИ РЕЧИТАТИВНЫХ ФОРМ В ОПЕРНОМ ТВОРЧЕСТВЕ К. МОНТЕВЕРДИ
}

В статье рассматриваются стилистические условия развития речитативной формы пения в оперном творчестве К. Монтеверди. Аналитическим путем доказывается связь речитативных интонационных формул с музыкально-риторическими фигурами. Выявляются эмоциональные предпосылки, образные условия введения речитативных формул в вокальный язык опер Монтеверди. Также определяется воздействие на речитативный строй пения специфического оперного словесного текста.

Ключевые слова: Монтеверди, опера, речитативные формулы.

В опере возникает и вместе с ней развивается особое речитативное слово, то есть особая разновидность словесного высказывания, подчиненная принципам музыкального произношения, вместе с тем эти принципы обусловливающая. Потребность в таком слове стала одной из главных причин появления оперного жанра и сопутствующего ему ораториального пения в Италии. А возникает данная по-

(C) Чжи Инь, 2014 
требность, на наш взгляд, из перенесения гомилетической функции словесной формы - как формы устного слова - из церковной сферы в светскую, то есть в процессе создания семантической альтернативы музыкально-театральной формы форме храмового ритуала, риторике церковного слова.

Клаудио Монтеверди - композитор, ставший одновременно и последним великим классиком мадригального письма, и первым классиком оперного искусства. Тема страдания, разработанная в его мадригалах, их взволнованная лирическая атмосфера, трагический колорит в большой мере перешли и в его оперное творчество. И хотя Монтеверди использовал получившие широкое распространение в период возникновения оперы и оратории мифологические сюжеты, обращаясь к ним, он стремится выразить в музыке реальное человеческое чувство в его трагических коллизиях.

Музыка Монтеверди способна к передаче острых противоречий, трагического. Но, воплощая трагические коллизии, Монтеверди словно поднимается над ними, прибегая к помощи речитативных формул, открывая с их помощью новые художественные возможности риторических фигур. Происходит это не в результате безоговорочного подчинения установленным образцам, а благодаря многочисленным отклонениям от них, нарушениям существующих норм. Монтеверди сам использует принцип построения музыкально-риторических фигур, проявляя при этом творческую индивидуальность и изобретательность.

Наиболее совершенным образцом зрелого стиля Монтеверди, вобравшим все самое характерное для его языка, является опера «Коронация Поппеи» (1642 г.), последнее сочинение композитоpa. В европейской музыке «Коронация Поппеи» - первая опера на исторический сюжет; одновременно это и первая музыкальная драма, в которой «с поистине шекспировской мощью обрисовываются живые, реальные люди, наделенные сильными противоречивыми характерами, и в результате их столкновений возникают остротрагические конфликтные ситуации, а развитие действия протекает необычайно напряженно, взрывчато» [72, с. 85].

Наша задача - выяснить, насколько важны для Монтеверди принципы речитатива как пути к установлению авторского стиля оперного творчества; определить степень смысловой подвижности одной и той же речитативной формулы у Монтеверди; степень канонизации выразительных средств (мелодии, гармонии, ритма, полифонии) и 
свободы Монтеверди в применении речитативных формул, для того чтобы определить степень самостоятельности и действенности музыкальных характеристик, связанных с материалом речитатива.

Установив, что Монтеверди достаточно широко использует в опере «Коронация Поппеи» приемы, заимствованные из музыкальнориторической системы, мы можем выделить большие группы, объединяющие в себе: фигуры, возникающие в результате следования установленным канонам; музыкальные приемы, принадлежащие самому Монтеверди и лишь опосредованно связанные с риторическими формулами.

В первой группе в большом количестве представлены музыкальные приемы, принадлежащие к изобразительным фигурам (группа hypotiposis): «В риторике - это представление (т. е. изображение) есть подобное, но весьма краткое деяние, изображаемое важными словами» [57, с. 362]. Преобладание нисходящего движения в мелодической линии (в партии Сенеки) связано с мыслью о приближении смерти и приготовлением к ней. Восходящее поступенное движение (фигура anabasis) возникает на словах Арнальты, радующейся своему возвышению («повластвовать пердставится возможность»). Аналогичный пример (также в партии Арнальты) - фигура anabasis на словах: «Раба я радом, а вот умру, а вот умру матроной». В соответствии с принятыми правилами использованы и фигуры тираты; так, например, тирата появляется в сопровождении слов о жестокости стихии, которую должна испытать отвергнутая Нероном Октавия. Встречается также сочетание одновременно двух фигур, например, catabasis (у оркестра) и фигуры вздоха в вокальной партии Нерона. Часто встречаются в опере также фигуры, относящиеся к группе фигур украшений или Manieren.

Наряду с внешней функцией украшения, Manieren часто являются важными выразительными приемами подчеркивания слов и весьма часто изобразительным средством.

Так, в диалогической сцене Поппеи и Оттона, когда последний завидует счастливому сопернику, слово «счастливец» выделено за счет использования фигуры украшения. Таким же образом выделено слово «lieta» в партии Сенеки («К тебе мой дух летит в светлом, светлом порыве»), когда посланец Олимпа Меркурий сообщает Сенеке о предстоящей последнему дороге в царство небожителей, его партия насыщена юбиляциями. Аналогичный пример - песня Нерона, воспевающего красоту своей возлюбленной, и далее фигуры украше- 
ний выделяют в дуэте Нерона и Лукана слова «сantiam», «amoroso», «ridente», «gloria» и другие; ликование Друзиллы по поводу вновь обретенной любви Оттона также выражено в музыке благодаря обилию украшений.

Число подобных примеров можно было бы умножить, но среди них есть и несколько отличающихся от прочих тем, что указанная фигура выполняет изобразительную, характеристическую, а не украшающую функцию. Так, подражание смеху происходит за счет применения украшений.

С помощью речитативных по интонационному рисунку формул композитор подчеркивает главное содержание сцены, а из общего контекста выделяются ключевые слова - ведущие значения. Квинтиллиан называл такие риторические приемы «приемами увеличения предмета».

Когда философ Сенека рассуждает о бренности земного величия и о смерти как победе человека над земными мучениями, в оркестре многократно повторяется неизменный двухтактовый мотив, одна часть которого напоминает секвенцию «Dies irae».

В сцене Октавии с Оттоном (приказывающей ему убить соперницу) использовано, на наш взгляд, весьма своеобразно сочетание фигур повторения и вопроса. В другом месте фигура повторения сочетается с фигурой украшения - на слове «Amor» в партии Поппеи. В эпизоде обвинения Друзиллы фигура повторения совмещается с фигурой вопроса. Этот прием способствует как передаче общего настроения «обвинителей» - одна и та же фраза повторяется в партии различных персонажей, так и напряженности ситуации, ее эмоциональной неустойчивости, благодаря вопросительному характеру повторяющейся мелодической фразы.

Широко применяются в опере такие речитативные формы, отличительным признаком которых являются особенности интонационного следования за словесной фразой. Так, неоднократно использована фигура interrogatio (лат. - вопрос), предполагающая ход мелодии на секунду вверх в конце предложения. В таком виде фигура вопроса звучит в обращении Сенеки к Меркурию: «За что, скажите мне, я сподобился чести видеть вас?».

С фигурами вопроса Монтеверди обращается свободно, так как применяет самые различные интервалы, завершающие мелодическую фразу. Так, вопрос одного из солдат завершен нисходящей квартой, а вопрос Оттона: «Но, что медлю, что медлю?», который он 
задает сам себе, намереваясь убить Поппею, изображен при помощи интервала нисходящей квинты. Когда Оттон обнаруживает измену Поппеи, его скорбный вопрос: «Но ... что вижу я, несчастный?» передан при помощи интервалов восходящей увеличенной квинты и восходящей малой секунды. В другом месте вопрос передается интонацией нисходящей секунды и терции - на словах: «Где я? Что со мной? Ужели то правда?» А в сцене Октавии с Оттоном взволнованные вопросы Оттона, потрясенного жестокостью императрицы, переданы при помощи интонаций восходящей терции (малой, затем большой), завершающей секвентно повторяющуюся фразу.

Из этой же группы мелодических фигур используется также фигура passus duriusculus (лат. - жестковатый ход) - самая характерная для музыки барокко фигура, не имеющая строгих образцов в риторических таблицах, лишь предполагающая наличие хроматики, - в виде отрезков хроматической гаммы или хроматических интервалов (ув. 2, ум. 4).

Применяется также родственная вышеуказанной фигура saltus duriusculus (жестковатый скачок), представляющая собою скачок на широкий, часто хроматический интервал с целью подчеркивания определенного слова. Как видно из характеристики фигуры passus duriusculus и производной от неe saltus duriusculus, они не были жестко регламентированы. Риторическая норма заключала в себе в данном случае свободу выбора. Композитору предоставлялось право самоопределения и самоограничения - в достаточно широких пределах выразительных приемов, носителями которых были фигуры определенной группы. Приведем примеры применения фигуры passus duriusculus: на словах «Императрица наша вся изошла слезами», «на какое истязание вы меня осудили», «Сколь юным мне погибать?».

В одном случае в оркестре звучит нисходящий хроматический ход от звука ми-бемоль к до, ему соответствует текст: «то сожаления слезою раннюю могилу ороси мне».

Как видим, данные фигуры использованы в тех случаях, когда необходимо было отразить в музыке напряженную скорбь, охватившую героя.

Вполне в соответствии с нормами использована фигура passus duriusculus и на словах Оттона: «моим моленьям вняло сердце, жемчужинами слез их украшая».

Тема полифонического хора домочадцев, прощающихся с Сенекой, соответствующая словам «non morir», также строится всецело на 
поступенных хроматических интонациях и является типичнейшей фигурой passus duriusculus.

Яркий образец фигуры saltus duriusculus встречается также в партии у Сенеки, обличающего императора-тирана - на словах: «Но и моя погибель не насытит Нерона»; отметим также фигуру catabasis, предшествующую в данном примере фигуре saltus duriusculus.

Для озвучивания слов, означающих состояние гнева, негодования, решимости используются ходы на различные интервалы.

Встречаемся мы также с использованием фигуры passus duriusculus, отражающей состояние любовного томления, неги на словах: «и лобзанья их ощущаю».

Как мы уже отмечали, сама риторическая система содержала возможность различной степени таких изменений - и буквального следования имевшимся в ней образцам нормативного музыкального письма, и свободного переосмысления фигур.

Конечно, в определенной степени при выборе музыкальных приемов (на различных уровнях музыкального языка оперы) Монтеверди руководствовался этической значимостью персонажей. Характеристика Нерона, Поппеи, Арнальты часто оказывается связанной с точным, подчеркнуто нормативным использованием музыкально-риторических фигур. Например, обильными украшениями, имитациями наполнен любовный дуэт Нерона и Поппеи; радость, охватившая Поппею при известии о ее восхождении на престол, также выражена при помощи украшений.

Это и использованная в партии Нерона фигура catabasis, упоминавшаяся ранее, она же в партии Поппеи; фигура anabasis у Арнальты, мечтающей о возвышении благодаря своей близости к Поппее. Нормативно озвучено слово «Прощай» в сцене расставания влюбленных Нерона и Поппеи фигурой saltus duriusculus.

В целом, для интонационной сферы Поппеи и Нерона в большей степени характерна диатоничность, хотя встречаются и фигуры, связанные с хроматическими отклонениями. Такова традиционно примененная в партии Поппеи фигура passus duriusculus для озвучивания слов: «да, гибель мне своим лишь звуком».

Нерон - император, повелевающий судьбами своих подданных, охарактеризован при помощи различных, производных от фигуры passus duriusculus комбинаций с интервалом кварты; терцовыми оборотами - в момент, когда гнев его по отношению к Друзилле смягчается и кварта уступает место терции. 
Характеризуя первый план персонажей, Монтеверди большей частью избирает те риторические формулы, которые были сами по себе более нормативными и устойчивыми. Но поскольку и эти образы претерпевают развитие, изменение, он избегает однозначности, смысловой упрощенности в их музыкальной обрисовке.

В этом отношении особенно интересны приемы, используемые Монтеверди для создания образа Поппеи. В целом ряде случаев он использует нормативные риторические фигуры. Но так как Поппея лицемерна, ею владеет лишь одна страсть - честолюбие, которое становится причиной жизненных драм, «диссонансов» многих героев оперы (например, страданий влюбленного в нее Оттона, ревности, страданий, изгнания из Рима законной жены Нерона Оттавии, смерть Сенеки), то в музыке, ее характеризующей, часто используется прием несоответствия смысла традиционных риторических формул данной эмоциональной ситуации, а также прием преувеличения выражения чувства, основанный на подчеркнутом, преувеличенно старательном следовании риторическим правилам.

Например, Поппея восхваляет Нерона, и на словах «славнейший из славных» звучит фигура saltus duriusculus, которая, хотя допускала различное использование, но в данном случае явно не соответствует хвалебным речам Поппеи и поэтому вызывает сомнение в достоинствах Нерона и искренности Поппеи.

На словах Поппеи «да, гибель мне своим лишь звуком» музыкальное сопровождение указывает на показной характер ее страданий.

Прием несоответствия музыкального выражения чувствам героини, противоречивое использование фигуры catabasis, применяется в сцене ликования Поппеи в связи с клятвой Нерона взять ее в жены.

Эта фигура, обычно выражающая состояние печали, горя, подавленности, в данном случае «обвиняет» Поппею. Любовь Поппеи и Нерона несет горе, мрак для других героев, именно этот ее роковой характер отражает фигура catabasis. Таким образом, Монтеверди создает настоящий контрапункт эмоциональных состояний.

Аналогичное несоответствие возникает при использовании фигуры catabasis в сцене триумфа Поппеи и Нерона на словах «но да будет в твоем триумфе самым лучшим и ценным трофеем, дорогая Поппея, любовь Нерона».

Император Нерон подвержен быстропроходящим страстям. Наряду с другими приемами музыкальной характеристики, музыкаль- 
но-риторические фигуры также участвуют в передаче противоречий его характера. Так, объяснение Нерона в любви сопровождается диссонирующими гармониями: «О, глаза моей милой, мне жизнь без вас постыла». В другом месте фигура tmesis (греч. - отделение, разрыв) призвана передать гнев, ярость, охватившие Нерона в споре с Сенекой.

Для характеристики персонажей, явившихся пострадавшими (а также Оттона - неустойчивой личности, но вызывающей сочувствие силой своего страдания), Монтеверди также часто прибегает к речитативным формулам. Но в большей мере именно при создании этих образов связь с риторической системой становится весьма опосредованной, трудноуловимой; встречаются такие примеры, для которых трудно предложить конкретные смысловые аналогии среди традиционных музыкально-риторических фигур. Таким образом, Монтеверди приходит к своим собственным, всецело оригинальным музыкальным приемам.

Многие приемы вокального голосоведения в опере «Коронация Поппеи» являются собственными изобретениями (inventio) Монтеверди, и трудно иной раз указать на какую-либо музыкально-риторическую фигуру, послужившую источником создания того или иного новшества.

Собственные речитативно-мелодические, интонационно связанные с мадригальной риторической таблицей фигуры изобретены композитором для передачи определенных чувств, состояний - скорби, печали, страдания, отчаяния, с одной стороны, и гнева, мстительности, героической решимости, настойчивости, душевного подъема, радостного ликования - с другой.

Так, в большом количестве использованы в опере интонационные обороты, ассоциирующиеся с различными оттенками чувства скорби. Ими насыщены партии наиболее трагических персонажей оперы: Октавии, Оттона. Отверженный обманутый Оттон, покинутая супругом ради новой возлюбленной императрица Октавия изображены в музыке сходными средствами. Наряду с вышеупомянутым применением различного рода музыкально-риторических фигур (вздоха, вопроса, passus duriusculus, saltus duriusculus) для их характеристики как наиболее уязвленных переживаниями персонажей использована хроматика, противоположная диатонике.

Такова, по преимуществу, интонационная сфера Октавии - обилие малосекундовых «скорбных», «плачущих» интонаций-речитаций. 
Таким образом, для создания скорбного образа Октавии Монтеверди использует хроматическое движение, часто в сочетании с нисходящей мелодией, скачками на уменьшенные интервалы и фигурой вздоха при подавляющем господстве минорного лада как обязательного компонента выразительности в данном случае. Как видим, совокупность этих элементов предвещает классическую арию lamento. Еще один выразительный прием - скорбная речитация на одном звуке в характеристике Октавии отражает ее отчаяние, безысходность ее положения.

Если мы сравним все эти принадлежащие Монтеверди музыкальные приемы с музыкально-риторическими фигурами, призванными передать аналогичные чувства (скорби, подавленности, отчаяния, желания смерти, страданий от неразделенной любви), то станет очевидной их общность. Хроматические изменения предполагает фигура предложений parrhesia, фигура passus duriusculus, фигура patopoja, скачки вниз на хроматические интервалы составляют суть фигуры saltus duriusculus. Секундовые интонации характерны для фигур вопроса, вздоха.

Таким образом, элементы будущего оперного речитатива как необходимой части мелодического материала оперы, соседствующего с арией и насыщающего ее своими интонационными изобретениями, возникают в творчестве Монтеверди в процессе сочетания и переосмысления приемов, особых музыкальных фигур, в теории получивших название риторических. В подтверждение этого вывода сошлемся на книгу В. Конен «Театр и симфония», в которой она прослеживает на большом количестве примеров становление различных типов оперных арий, а том числе и арии lamento. Отметим, что в качестве одного из первооткрывателей выразительных приемов арии lamento она называет Монтеверди, и в нотных примерах часто ссылается на его произведения, в том числе и на анализируемую нами оперу. В частности, о последнем монологе Октавии (в сцене прощания с Римом) Конен пишет: «Из этого последнего lamento черпали идеи многие будущие оперные композиторы, не только до Перселла и Генделя, но вплоть до Глюка и Моцарта» [2, c. 301-302].

«Коронация Поппеи» - последняя опера Монтеверди, поэтому естественно, что в ней обобщены достижения всего его творчества, а в использовании тех или иных оборотов усиливается эмоциональнопсихологическая направленность. 
В произведениях Монтеверди музыкальные приемы, связанные с эмоциональными сферами скорби и героики, постепенно канонизируются и становятся эталонами в его собственном творчестве, а позже в творчестве последующих за ним оперных композиторов. Эти приемы, возникшие первоначально в результате буквального и частичного, опосредованного заимствования риторических фигур, а также впоследствии сделанного на основе риторических формул inventio (открытия) и самого общего следования риторическому принципу построения музыкальных фигур, развиваясь и совершенствуясь, становятся такими же нормами, как исходные музыкальнориторические фигуры. За ними закрепляются определенные смысловые значения, которые впоследствии станут основой для круга средств музыкальной выразительности классицистских оперных арий lamento и героической арии (арии мести). А еще позже, освободившись от зависимости от словесного текста, они станут основой речитативного инструментального тематизма, вырвавшись из словесно-сценического контекста.

Творчество Монтеверди стало связующим звеном между двумя системами норм и правил музыкального выражения - ренессансно-барочной и классицистской. При этом музыкальный язык опер Монтеверди был нормированным скорее с позиций будущего искусства классицизма, в котором музыка становится самоценным видом, в полной мере проявившим свою художественную специфику. Вместе с тем общей логикой композиции и мелодико-тематического мышления Монтеверди, несомненно, обязан музыкальной риторике XVI-XVII веков, из которой он извлек важнейшие для музыкального языка оперы принципы смыслообразования.

\section{СПИСОК ЛИТЕРАТУРЫ}

1. Захарова О. Музыкальная риторика XVII - первой половины XVIII века / О. Захарова // Проблемы музыкальной науки. - М. : Сов. композитор, 1975. - Вып. 3. - С. 345-378.

2. Конен В. Клаудио Монтеверди / В. Конен. - М. : Советский композитор, 1971. - $323 \mathrm{c}$.

Чжі Інь. Риторичні витоки речитативних форм в оперній творчості K. Монтеверді. У статті розглядаються стилістичні умови розвитку речитативної форми співу в оперній творчості К. Монтеверді. Аналітичним шляхом доводиться зв'язок речитативних інтонаційних формул з музично-риторичними фігурами. Виявляються емоційні передумови, образні фактори запро- 
вадження речитативних формул до вокальної мови опер Монтеверді. Також визначається вплив на речитативний лад співу специфічного оперного словесного тексту.

Ключові слова: Монтеверді, опера, речитативні формули.

Zhi In. Rhetorical sources of recitative forms are in opera work of $\mathrm{K}$. Monteverdi. The article consider the stylistic terms of development of recitative form of singing in the K. Monteverdi's opera work. The connection of recitative intonation formulas with musically-rhetorical figures is proved by analytical way. The emotional pre-conditions, imaginative terms of introduction of recitative formulas, of the vocal language of operas of Monteverdi are detected. The affecting on the recitative formation of singing of specific opera verbal text is also determined.

Keywords: Monteverdi., opera, recitative formulas. 